\title{
Commentary \\ Matrix metalloproteinases and their inhibitors: promising novel biomarkers in severe sepsis?
}

\author{
Ursula Hoffmann, Martina Brueckmann and Martin Borggrefe
}

1st Department of Medicine, Faculty of Medicine Mannheim, University of Heidelberg, Theodor-Kutzer-Ufer 1-3, D-68167 Mannheim, Germany

Corresponding author: Ursula Hoffmann, Ursula.Hoffmann@umm.de

Published: 1 December 2009

Critical Care 2009, 13:1006 (doi:10.1186/cc8156)

This article is online at http://ccforum.com/content/13/6/1006

(c) 2009 BioMed Central Ltd

See related research by Lorente et al., http://ccforum.com/content/13/5/R158

\begin{abstract}
The multicenter study conducted by Lorente and coworkers published in the previous issue of Critical Care demonstrates that matrix metalloproteinase (MMP)-9 and MMP-10 and their inhibitor tissue inhibitor of matrix metalloproteinase-1 (TIMP-1) are promising novel biomarkers to predict severity and outcome of sepsis. In recent years MMPs have emerged as biomarkers in a variety of diseases, such as sepsis, coronary artery disease, cancer, heart failure, chronic lung disease and rheumatoid arthritis. MMPs constitute a family of proteinases that are expressed during developmental, physiological, and pathophysiological processes, for example as a response to infection. Excessive inflammation following infection may cause tissue damage, and MMPs are implicated in causing this immunopathology. The activity of MMPs is regulated by secretion of specific inhibitors (TIMPs). Studies using MMP inhibitors and MMP knockout mice indicate that MMPs play an essential role in infection and in the host response to infection. The measurement of MMP-9 and MMP-10 and their inhibitor TIMP-1 in the intensive care setting could be an attractive noninvasive tool for determination of outcome of septic patients.
\end{abstract}

\section{Introduction}

In the previous issue of Critical Care, Lorente and coworkers reported the results of a prospective cohort study evaluating matrix metalloproteinases (MMPs) and tissue inhibitors of metalloproteinases (TIMPs) as potential biomarkers for the determination of sepsis severity and for the prediction of mortality in septic patients [1]. The authors found that nonsurviving septic patients presented with lower MMP-9 levels, higher TIMP-1 levels and a lower MMP-9/TIMP-1 ratio. Moreover, they showed that TIMP-1 levels can predict the clinical outcome of septic patients and could be useful for risk stratification of patients with sepsis.

MMPs have been shown to be important in the pathogenesis and development of inflammatory diseases and are intimately involved in the regulation of the activities of cytokines and cytokine receptors [2]. Pathophysiologically, a successful eradication of infection by the host requires the influx of effector cells into the infected tissue, killing of the pathogen, resolution of inflammation and, finally, remodeling of the extracellular matrix. Excessive inflammation following infection may cause tissue damage, however, and MMPs are implicated in causing this immunopathology [3].

Several mechanisms account for increased MMP and TIMP levels in the setting of sepsis. First of all, human neutrophils secrete gelatinase B (MMP-9) in vivo and in vitro in response to endotoxin and proinflammatory mediators such as TNF $\alpha$ or IL-8 [4]. Secondly, TIMP-1 can activate normal human granulocytes, protecting them from apoptosis and blocking their transmigration during inflammation [5].

Elevated serum levels of MMPs have been described in some studies in response to endotoxin and proinflammatory mediators [4], and MMPs can be considered as markers of inflammation in various diseases $[6,7]$. Studies that investigate MMPs and their inhibitors in septic diseases are rare and have involved only limited numbers of patients. MMP-9 levels have been shown to be elevated in patients with severe sepsis compared with healthy control individuals $[8,9]$. In a small study of 20 patients with septic shock, Nakamura and colleagues found elevated MMP-9 levels in nonsurvivors of severe sepsis as compared with survivors and healthy controls [10]. Unfortunately, Lorente and coworkers cannot confirm these results in their multicenter study [1]; on the contrary, these authors show lower MMP-9 and a reduced MMP-9/TIMP-1 ratio in nonsurviving septic patients [1]. In accordance with a previous study [9], the TIMP-1 values were higher in septic patients. Moreover, TIMP-1 levels were shown to have prognostic implications in severe septic patients as has been described before $[1,9]$. Lorente and

$\mathrm{IL}=$ interleukin; $\mathrm{MMP}=$ matrix metalloproteinase; TIMP $=$ tissue inhibitor of matrix metalloproteinase; $\mathrm{TNF}=$ tumor necrosis factor. 
coworkers define an elevated risk of death in septic patients with a cut-off value $>531 \mathrm{ng} / \mathrm{ml}$ for TIMP- 1 according to their receiver operating curve analysis [1]. This result is quite different to another study in septic patients, which evaluated a cut-off value $>3,200 \mathrm{ng} / \mathrm{ml}$ for TIMP [9]

Importantly, Lorente and colleagues could show an association of MMP-9, MMP-10 and TIMP-1 with the severity of sepsis and a correlation of these parameters with markers of inflammation on the time of diagnosis of sepsis [1], which was not demonstrated in a previous study in septic patients [9].

A limitation of the study by Lorente and colleagues, however, is the lack of serial measurements of MMPs and TIMPs over several days, which could help to confirm the association between these markers with the severity of sepsis as assessed by the Sequential Organ Failure Assessment score and Acute Physiology and Chronic Health Evaluation score.

\section{Matrix metalloproteinases and tissue inhibitors of metalloproteinases as biomarkers in the intensive care unit}

Recent data and cumulative analysis indicate that biomarkers improve diagnosis of sepsis and may help to predict the prognosis of septic patients. Biomedical scientists are aggressively investigating biomarkers of disease and injury.

In the scene of sepsis biomarkers, C-reactive protein, IL-6 and procalcitonin are the most investigated markers in clinical trials. In recent published studies, procalcitonin is of better value for diagnosis and prognosis of sepsis when compared with markers such as C-reactive protein or with proinflammatory cytokines such as IL-6 [11-13]. There are additional new sepsis markers with so far limited clinical evidence, for example triggering receptor on myeloid cells or $\mathrm{N}$-terminal pro-brain natriuretic peptide [14,15]. Unfortunately, biomarkers rarely alter our clinical decision-making in severe sepsis as they are often nonspecific, lack adequate sensitivity and/or are difficult to measure and to interpret accurately.

Metalloproteinases and their inhibitors may represent a promising new class of biomarkers for the prognosis of severe sepsis patients. The development of specific inhibitors of MMPs [16] or TIMPs as a new class of drugs for sepsis therapy is challenging, and future clinical trials have to clarify their role within the treatment regime of septic patients.

\section{Conclusion}

The use of biomarkers may improve early diagnosis and therapy in critically ill patients, and may consecutively influence the morbidity and mortality of these patients.

The implementation of metalloproteinases and their inhibitors as new biomarkers for the severity of sepsis and for mortality in critically ill patients may provide promising decision support for the intensivist to guide the allocation of hospital resources. Additional larger studies are needed, however, to determine the cellular origin and the relevance of these enzymes in sepsis.

\section{Competing interests}

$\mathrm{MBr}$ is an employee of Boehringer Ingelheim $\mathrm{GmbH}$, Germany. The other authors declare that they have no competing interests.

\section{Acknowledgements}

The present work was supported by a grant of the Faculty of Medicine Mannheim, University of Heidelberg, Germany.

\section{References}

1. Lorente L, Martin MM, Labarta L, Diaz C, Solé-Violán J, Blanquer J, Orbe J, Rodriguez JA, Jiménez A, Borreguero-Léon JM, Belmonte F, Medina JC, LLiminana MC, Ferrer-Agüero JM, Ferreres J, Mora ML, Lubillo S, Sánchez M, Barrios Y, Sierra A, Páramo JA: Matrix metalloproteinase-9, -10 , and tissue inhibitor of matrix metalloproteinases-1 blood levels as biomarkers of severity and mortality in sepsis. Crit Care 2009, 13:R158.

2. Opdenakker G, Van den Steen PHE, Van Damme J: Gelatinase B: a tuner and amplifier of immune functions. Trends Immunol 2001, 22:571-579.

3. Elkington PTG, O'Kane CM, Friedland JS: The paradox of matrix metalloproteinases in infectious disease. Clin Exp Immunol 2005, 142:12-20.

4. Pugin J, Widmer MC, Kossodo S, Liang CM, Preas II HL, Suffredini AF: Human neutrophils secrete gelatinase $B$ in vitro and in vivo in response to endotoxin and proinflammatory mediators. Am J Respir Cell Mol Biol 1999, 20:458-464.

5. Chromek M, Tullus K, Lundahl J, Brauner A: Tissue inhibitor of metalloproteinase 1 activates normal human granulocytes, protects them from apoptosis, and blocks their transmigration during inflammation. Infect Immun 2004, 72:82-88.

6. Kotyza J, Pesek M, Puzman P, Havel D: Progelatinase B/matrix metalloproteinase-9 proenzyme as a marker of pleural inflammation. Exp Lung Res 2004, 30:297-309.

7. Ferroni P, Basili S, Martini F, Cardarello CM, Ceci F, Di Franco M, Bertazzoni G, Gazzaniga PP, Alessandri C: Serum metalloproteinase 9 levels in patients with coronary artery disease: a novel marker for inflammation. J Investig Med 2003, 51:295300 .

8. Yassen KA, Galley HF, Webster NR: Matrix metalloproteinase-9 concentrations in critically ill patients. Anaesthesia 2001, 56:729-732.

9. Hoffmann U, Bertsch T, Dvortsak E, Liebetrau C, Lang S, Liebe V, Huhle G, Borggrefe M, Brueckmann M: Matrix-metalloproteinases and their inhibitors are elevated in severe sepsis: prognostic value of TIMP-1 in severe sepsis. Scand J Infect Dis 2006, 38:867-872.

10. Nakamura T, Ebihara I, Shimada N, Shoji H, Koide H: Modulation of plasma metalloproteinase- 9 concentrations and peripheral blood monocyte mRNA levels in patients with septic shock: effect of fiber-immobilized polymyxin B treatment. Am J Med Sci 1998, 316:355-360.

11. Harbarth S, Holeckova K, Froidevaux C, Pittet D, Ricou B, Grau GE, Vadas L, Pugin J: Diagnostic value of procalcitonin, interleukin- 6 and interleukin- 8 in critically ill patients admitted with suspected sepsis. Am J Respir Crit Care Med 2001, 164:396402.

12. Castelli GP, Prognani C, Meisner M, Stuani A, Bellomi D, Sgarbi $\mathrm{L}$ : Procalcitonin and $\mathrm{C}$-reactive protein during systemic inflammatory response syndrome, sepsis and organ dysfunction. Crit Care 2004, 8:R234-R240.

13. Clech C, Ferriere F, Karoubi P, Fosse JP, Cupa M, Hoang $P$, Cohen Y: Diagnostic and prognostic value of procalcitonin in patients with septic shock. Crit Care Med 2004, 32:1166-1169.

14. Roch A, Allardet-Servent J, Michelet P, Oddoze C, Forel JM, Barrau K, Loundou A, Perrin G, Auffray JP, Portugal H, Papazian $\mathrm{L}$ : $\mathrm{NH}_{2}$ terminal pro-brain natriuretic peptide plasma level as an early marker of prognosis and cardiac dysfunction in septic shock patients. Crit Care Med 2005, 33:1001-1007. 
15. Gibot $S, P e$ LR, Bollaert PE, Kolopp-Sarda MN, Béné MC, Faure GC, Lévy B: Surface triggering receptor expressed on myeloid cells 1 expression patterns in septic shock. Intensive Care Med 2005, 31:594-597.

16. Lalu MM, Gao CQ, Schulz R: Matrix metalloproteinase inhibitors attenuate endotoxemia induced cardiac dysfunction: a potential role for MMP-9. Mol Cell Biochem 2003, 251:61-66. 